\title{
Lingual angioedema with macroglossia during the treatment of acute ischemic stroke with alteplase
}

This article was published in the following Dove Press journal:

International Journal of General Medicine

27 February 2012

Number of times this article has been viewed

\section{Josef Yayan}

Department of Internal Medicine, Vinzentius-Hospital, Landau, Germany
Correspondence: Josef Yayan

Department of Internal Medicine, Vinzentius-Hospital, Cornichonstraße 4,

D-76829 Landau, Germany

$\mathrm{Tel}+49634 \mid \quad 176128$

Fax +49634I I7 2204

Email josef.yayan@hotmail.com

\begin{abstract}
Alteplase (recombinant tissue plasminogen activator) has been used in the treatment of acute ischemic stroke for 10 years. The application of this drug is considered safe and effective. However, alteplase is also associated with side effects. The author is reporting on an unual side effect of angioedema that is triggered by alteplase. Angioedema occurs through alteplase according to this study at a frequency of $5.88 \%$ (95\% confidence interval: $0.98 \%$ to $28.76 \%$ ). In this case immunoglobulin $\mathrm{G}$ was slightly increased. The relative risk to get an angioedema compared between the two genders is elevated in men 3.3 (95\% confidence interval: $0.15 \%$ to $71.90 \% ; P=0.4423$ ), who were 3.3 times more likely to suffer than women. The use of angiotensin-converting-enzyme (ACE) inhibitors is considered a possible risk factor for the occurrence of angioedema with concomitant administration of tissue plasminogen activator. The angioedema may occur with use of alteplase at any time, so treatment with this drug must always be carried out in intensive care and doctors must be ready for intubation if necessary.
\end{abstract}

Keywords: angioedema, macroglossia, alteplase, ischemic stroke

\section{Introduction}

Recombinant tissue plasminogen activator (rt-PA) has been used for a long time in the therapy of acute ischemic insult. The application of intravenous thrombolysis for ischemic stroke has already been established as a standard treatment throughout the world. For various reasons, however, only a small proportion of ischemic stroke patients were treated with alteplase, ${ }^{1}$ so we know little about the side effects of this drug. Hypersensitivity to alteplase is uncommon and has been estimated to occur in less than $0.02 \%$ of patients who receive it for the treatment of acute myocardial infarction. ${ }^{2}$ However, anaphylactic reaction by alteplase may also occur more in acute ischemic stroke patients. ${ }^{2} \mathrm{~A}$ little known complication of acute stroke treatment with systemic rt-PA thrombolysis is orolingual angioedema. This has occurred in $2 \%$ of patients for thrombolysis. ${ }^{3}$ There is an increased risk for the occurrence of angioedema during the therapy with alteplase, ${ }^{3,6,10}$ especially in patients receiving angiotensin-converting enzyme inhibitors. Angiodema by alteplase is usually only reported on from larger clinics so this present study is unique because it has been performed in a peripheral hospital with a small stroke unit. This means that the results of this study, combined with those of previous studies, can offer greater insight by discussing a broader spectrum than was previously available.

\section{Case presentation}

Among the patients given recombinant tissue plasminogen activator intravenously for acute ischemic stroke in this hospital (Vinzentius-Hospital, Landau, Germany), one 
had lingual angioedema. This was a 63-year-old patient, who was at home in bed at $11 \mathrm{pm}$. His wife came into the bedroom and saw her husband lying motionless and mute in bed. She was terrified and immediately alerted the emergency services. The emergency doctor was on site as soon as possible. He diagnosed a right hemiparesis and dysphasia, possibly due to a stroke. After arriving at hospital, a cranial CT to exclude intracranial hemorrhage was performed. After exclusion of contraindications for thrombolytic therapy, it was suggested that lysis with alteplase could solve a left-sided media infarction with flaccid hemiparesis on the right, right-sided facial paralysis, dysphasia, and dysphagia. His bleeding was within normal limits. Additionally, and unrelated to the onset of the current problem, he had arterial hypertension, diabetes mellitus type 2 , obesity, and chronic obstructive pulmonary disease. The man was taking a beta-blocker, angiotensinconverting-enzyme (ACE) inhibitor and, if needed for pain relief, non-steroidal anti-inflammatory drugs (NSAIDs), diuretics, inhalants, and benzodiazepine. The patient met the criteria for intravenous alteplase treatment of acute ischemic stroke (within a window of time of 80 minutes) and was given $0.9 \mathrm{mg} / \mathrm{kg}$ alteplase after a $10 \%$ bolus initially with the remaining drug infused over 60 minutes. Due to his high body weight (120 kilograms), the maximum dose of $90 \mathrm{mg}$ of alteplase was prescribed.

After intravenous administration of $80 \mathrm{mg}$ alteplase, the patient suddenly had trouble breathing. His tongue was swollen and he fought for breath. His entire body was blue and gray in color. He had to be reanimated and intubated immediately. The alteplase infusion was stopped at this time. The patient then received high-dose cortisone, antihistamine, and catecholamine. Later, he had to be tracheotomized. The next day, a head computerized tomography (CT) scan was performed and no hemorrhage could be seen but a big demarcation of the left middle cerebral artery was inspected. The patient ultimately spent 18 days in intensive care. He recovered from the angioedema, but his right hemiparesis, speech disturbance, and dysphagia remained.

After this event, all records of patients with stroke after thrombolytic therapy were examined for similar events in order to avoid angioedema by alteplase in the future.

The aim of this study was to determine the incidence of angioedema by alteplase in a peripheral hospital with a minor stroke unit in comparison to other published results. Furthermore, this study aims to answer the question whether the occurrence of angioedema through alteplase is dependent on other factors, such as the number of thrombolysis occurrences.

\section{Materials and methods}

This is a retrospective study of clinical data belonging to 730 patients. The criterion for inclusion was all patients had cerebral ischemia followed by thrombolysis. The author found a total of 17 patients that fit this criterion. All stroke patients in this study had their heads scanned by CT or magnetic resonance imaging (MRI). These patients were also examined by a neurologist. A CT scan of all patients was done in order to exclude a brain hemorrhage, prior to thrombolysis. All contraindications before lysis were excluded. The lysis therapy was carried out within the time frame of 3 hours for all stroke patients. After performing the thrombolysis, all patients were checked by a brain CT.

\section{Results}

The author thoroughly examined records of 730 patients after cerebral ischemia that underwent thrombolysis. After further research, the author found just 17 ischemic stroke patients who had undergone alteplase treatment. These consisted of eight men $47.06 \%$ (95\% confidence interval: $+/-23.73 \%, 23.33 \%$ to $70.79 \%$ ) and nine women $52.94 \%$ (95\% confidence interval: $+/-23.73 \%, 29.21 \%$ to $76.67 \%$ ) (Figure 1). These patients all had cerebral ischemia and severe clinical symptoms and were treated by lysis with alteplase within the therapeutic time frame of 3 hours. The average age of these patients was 69.94 years with a standard deviation of 11.82 years. A 63-year-old male patient had an angioedema with macroglossia during the treatment with alteplase in this hospital. The immunoglobulin $\mathrm{E}$ of this patient was within the reference range of immunoglobulin $\mathrm{E}(0-150 \mathrm{U} / \mathrm{mL})$. His immunoglobulin E was $5.4 \mathrm{U} / \mathrm{mL}$. The immunoglobulin $\mathrm{G}$ from this patient with macroglossia during treatment with alteplase was slightly increased at $17.4 \mathrm{~g} / \mathrm{L}$ at a reference range from 7 to $16 \mathrm{~g} / \mathrm{L}$. The immunoglobulin $\mathrm{M}$ from this patient was within the normal range.

\section{Statistical analysis}

The author measured the relative chance of cases having a positive outcome for both sexes with angioedema and without side effects. The proportion of cases having a positive outcome in angioedema under treatment with alteplase was 3.3 (95\% confidence interval: $0.15 \%$ to $71.90 \%),(P=$ $0.4423)$ between male and female. The odds of getting an angioedema under alteplase in two groups of men and women was 3.8 (95\% confidence interval: $0.13 \%$ to $107.32 \%),(P=$ $0.4335)$. The disease prevalence in angioedema under treatment with alteplase was 5.88\% (95\% confidence interval: $0.98 \%$ to $28.76 \%$ ). 


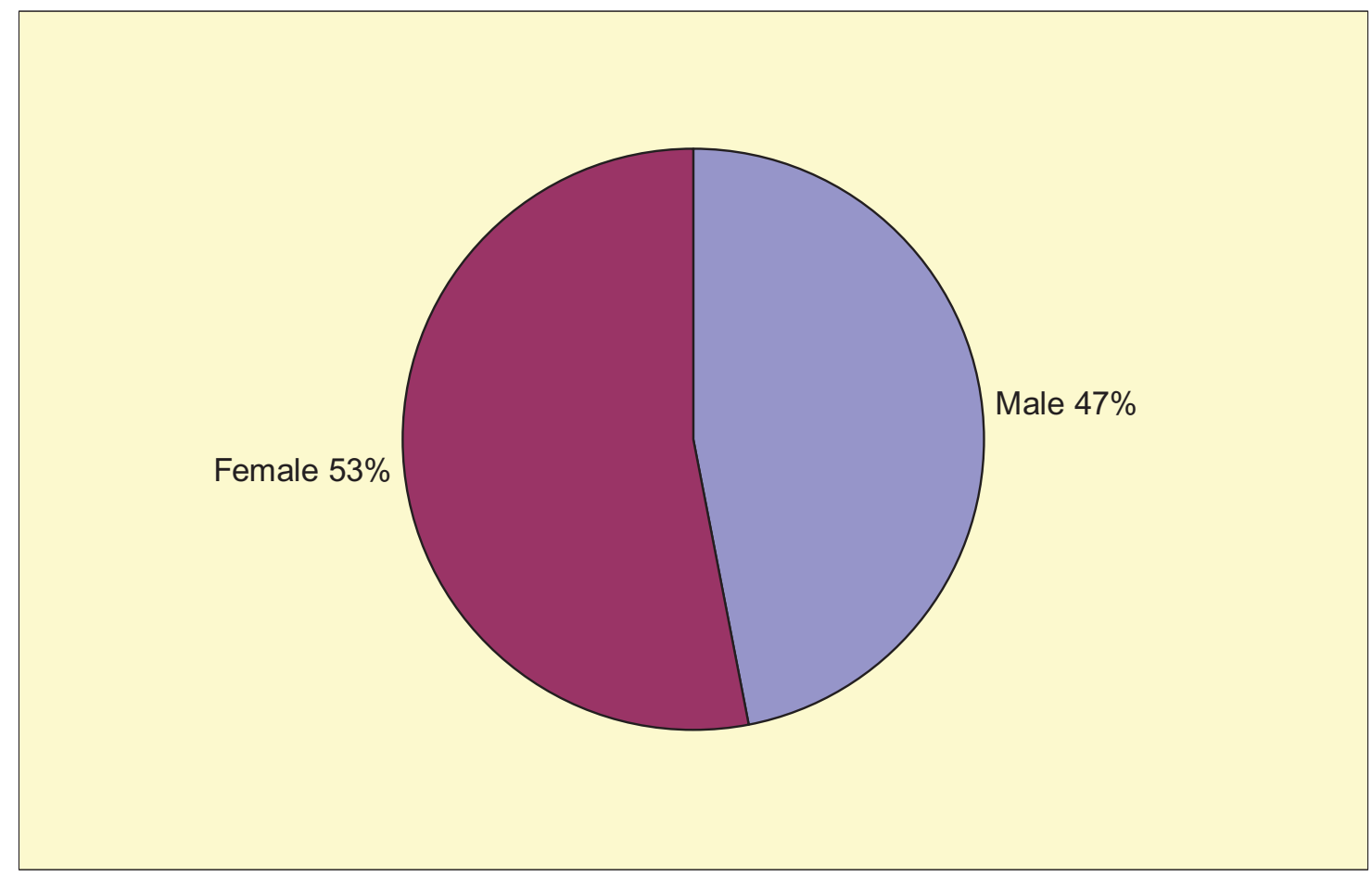

Figure I The gender distribution of thrombolysis in 17 ischemic stroke patients with alteplase treatment.

The sensitivity, specificity, as well as disease prevalence were expressed as percentages for interpretation. The sensitivity is the probability that a test result will be positive when an angioedema under alteplase is present. The specificity is the probability that a test result will be negative when an angioedema under alteplase is not present. The sensitivity and the specificity were $100 \%$.

The two-sided significance of independence by Fisher's exact test was calculated for angioedema by alteplase in the thrombolysis of patients with acute ischemic stroke. The two-sided significance was $P$-value of 0.471 .

\section{Discussion}

Although the application of tissue plasminogen activator has been established as a standard therapy for ischemic stroke globally, it is known that a small proportion of patients are currently treated with thrombolytic drugs. ${ }^{1}$

It was remarkable to learn that only a small number of therapies use alteplase. According to the results of this study, the occurrence of angioedema as a side effect by the administration of alteplase does not depend on the number of thrombolysis occurrences.

Allergic reactions to thrombolysis can occur but are most commonly seen during therapy with streptokinase. ${ }^{4,5}$ Allergic reactions may also occur as reported in rare cases in the treatment of myocardial infarction with alteplase. ${ }^{5}$
The aforementioned orolingual angioedema by alteplase was reported in recent studies. ${ }^{3}$ The prevalence of the disease was increased to three times in this study of angioedema under treatment with alteplase, as compared with other studies. The frequency of side effects under alteplase is the same in the present study as it is in studies published in other literature. ${ }^{6}$ Hill and colleagues reported in their work the similar prevalence of reaction with orolingual angioedema after alteplase treatment of stroke. ${ }^{6}$ In view of these studies, the incidence of orolingual angioedema under treatment with alteplase of ischemic stroke seems to undergo a significant variations.

Immunoglobulin $\mathrm{G}$ or $\mathrm{M}$ were found to be increased in the serum some days or weeks after therapy with alteplase.

In this case, immunoglobulin $\mathrm{G}$ from this patient with macroglossia during treatment with alteplase was slightly increased. The immunoglobulin $\mathrm{M}$ from this patient was within the normal range.

The immunoglobulin E antibody was found in the serum of one patient with anaphylaxis under treatment with alteplase. ${ }^{8}$ The immunoglobulin E was normal in this study.

The angioedema as a side effect of alteplase seems to arise rapidly even during treatment, as in this case. Also, in the two patients studied by Hill and his colleagues, the angioedema occurred within 1 hour. $^{2}$ 
A possible cause of orolingual angioedema by alteplase is thought to be the concomitant use of ACE inhibitors, as suggested in various scientific literature. Risk of angioedema by alteplase was associated with angiotensin-converting enzyme inhibitors with a relative risk of $13.6 \%$, such as Hill and his colleagues described. ${ }^{6}$

Also Krmpotic and Fernandes described an increased risk of anaphylaxis in patients concomitantly being treated with angiotensin-converting enzyme inhibitors, as illustrated in a case report describing a patient who experienced an urticarial rash, hypotension, tachycardia, orolingual angioedema, and airway obstruction following intravenous administration of alteplase. ${ }^{9}$ Possible pharmacologic interactions resulting in excessive serum bradykinin and subsequent systemic hypersensitivity responses are discussed. ${ }^{9}$

Okada reported a 75-year-old woman with an orolingual angioedema considered as a complication associated with alteplase and taking ACE inhibitors. ${ }^{10}$

Also, the patient in this study took an ACE inhibitor to control blood pressure. An interaction between his ACE inhibitor and the treatment with alteplase is assumed to be likely.

\section{Conclusion}

Orolingual angioedema is a potentially life-threatening complication of treatment with alteplase in acute ischemic stroke. This complication can occur under treatment at any time. Therefore, the administration of this drug is carried out in intensive care. The advice, according to the findings of this study, is the introduction of a Guedel airway tube in the mouth of the patient with acute ischemic stroke prior to the thrombolysis with alteplase for at least four hours with the readiness of an imminent possible intubation.

\section{Disclosure}

The author reports no conflicts of interest in this work.

\section{References}

1. Micieli G, Marcheselli S, Tosi PA. Safety and efficacy of alteplase in the treatment of acute ischemic stroke. Vasc Health Risk Manag. 2009;5:397-409.

2. Hill MD, Barber PA, Takahashi J, et al. Anaphylactoid reactions and angioedema during alteplase treatment of acute ischemic stroke. CMAJ. 2000;162:1281-1284.

3. Ottomeyer C, Sick C, Hennerici MG, Szabo K. Orolingual angioedema under systemic thrombolysis with rt-PA: an underestimated side effect. Nervenarzt. 2009;80:459-463.

4. Tsang TS, Califf RM, Stebbins AL, et al. Incidence and impact of on outcome streptokinase allergy in the GUSTO-1-trial. Global Utilization of Streptokinase and t-PA in Occluded Coronary Arteries. Am J Cardiol. 1997;79:1232-1235.

5. White HD, Cross DB, William BF, et al. Safety and efficacy of repeat thrombolytic treatment after acute myocardial infarction. Br Heart J. 1990;64:177-181.

6. Hill MD, Lye T, Moss H, et al. Hemi-orolingual angioedema and ACE inhibition after alteplase treatment of stroke. Neurology. 2003;60:1525-1527.

7. Cugno M, Cicardi M, Colucci M, Bisiani G, Merlini PA, Spinola A, et al. Non neutralizing antibodies to tissue type plasminogen activator in the serum of acute myocardial infarction patients treated with the recombinant protein. Thromb Haemost. 1996;76:234-238.

8. Rudolf J, Grond M, Prince WS, Schmülling S, Heiss WD. Evidence of anaphylaxy after alteplase infusion. Stroke. 1999;30:1142-1143.

9. Krmpotic KR, CM. Anaphylactoid reaction to recombinant tissue plasminogen activator. Eur J Emerg Med. Febuary 2007;14: $60-61$.

10. Okada Y, Shibazaki K, Sakai K, Kobayashi K, Iguchi Y, Kimura $\mathrm{K}$. Orolingual angioedema as complication after rt-PA in stroke patient treated with ACE inhibitor. Rinsho Shinkeigaku. 2008;48: $278-280$.
International Journal of General Medicine

\section{Publish your work in this journal}

The International Journal of General Medicine is an international, peer-reviewed open-access journal that focuses on general and internal medicine, pathogenesis, epidemiology, diagnosis, monitoring and treatment protocols. The journal is characterized by the rapid reporting of reviews, original research and clinical studies across all disease areas.

\section{Dovepress}

A key focus is the elucidation of disease processes and management protocols resulting in improved outcomes for the patient. The manuscript management system is completely online and includes a very quick and fair peer-review system. Visit http://www.dovepress.com/ testimonials.php to read real quotes from published authors. 